\title{
Los vuelcos en la Iglesia De Ratzinger a Bergoglio
}

\author{
OLEGARIO GONZÁLEZ DE CARDEDAL \\ Universidad Pontificia de Salamanca (España) \\ ogonzalezhe@upsa.es
}

\begin{abstract}
Resumen
En este artículo se ofrece una reflexión teológica sobre el significado que envuelve la elección de los últimos pontífices de la Iglesia católica que va desde Juan Pablo II, pasando por Benedicto XVI, hasta llegar al actual Papa Francisco. A juicio del autor, esta historia de la Iglesia en el último medio siglo ofrece aspectos sorprendentes que pueden llamarse mutaciones, giros, cambios de curso o vuelcos que incitan a preguntar si se trata de continuidad y de un real acrecentamiento, o por el contrario, de real ruptura; más todavía, surge la pregunta de si ante tales variaciones no estaremos ante un hecho de fondo más grave: que el cristianismo sea un sincretismo en el que todo cabe, capaz por tanto de asumir e integrar aun lo más diverso y contradictorio.
\end{abstract}

Palabras clave: Juan Pablo II, Ratzinger/Benedicto XVI, Bergoglio/Francisco.

\section{Rollovers in the Church \\ From Ratinger to Bergoglio}

\begin{abstract}
This article offers a theological reflection on the meaning surrounding the election of the last popes of the Catholic Church that go from John Paul II, through Benedict XVI, up to the present Pope Francis. According to the author, this story of the Church in the last half century gives striking aspects that can be called mutations, turns, changes of course or rollovers which incite to ask if this is a real continuation and enhancement, or on the contrary, true rupture; or even maybe, whether such variations show a much more serious fact arising in the background: that Christianity is syncretic, a system in which anything fits, thus being able to take and integrate even the most diverse and contradictory ideas.
\end{abstract}

Key words: John Paul II, Ratzinger/Benedict XVI, Bergoglio/Francis.

Doctor en Teología por la Universidad de Munich (Alemania). Durante largos años fue catedrático de la Universidad Pontificia de Salamanca hasta su jubilación en 2004. Fue miembro de la Comisión Teológica Internacional, del Pontificio Consejo para la Cultura, Consultor del Consejo Pontificio para el diálogo con los no Creyentes y y asistente al Concilio Vaticano II. Académico de Número de la Real Academia de Ciencias Morales y Políticas. Autor de numerosos libros entre los que se cuentan Cristología (2001), Ratzinger y Juan Pablo II: la Iglesia entre dos milenios (2005), Fundamentos de Cristología. I, El camino (2005) y II, Meta y misterio (2006), El quehacer de la teología (2008), La teologia en España (1959-2009): memoria y prospectiva (2010) y El rostro de Cristo (2011, reed. 2013). 


\section{Introducción: El último medio siglo y el último decenio de la Iglesia}

La historia de la iglesia católica en el último medio siglo ofrece aspectos sorprendentes. Llámeselos mutaciones, giros, cambios de curso o vuelcos; en cualquier caso incitan a preguntar si se trata de continuidad y de un real acrecentamiento, o por el contrario de real ruptura; más todavía, si ante tales variaciones no estaremos ante un hecho de fondo más grave: que el cristianismo sea un sincretismo en el que todo cabe, capaz por tanto de asumir e integrar aun lo más diverso y contradictorio.

El inicio de esa historia de abertura a la conciencia histórica y de integración de las orientaciones que fueron surgiendo con posterioridad a la Ilustración, a los movimientos sociales del siglo XIX y a la guerra mundial, no tiene lugar por el impulso de un papa intelectual, jurista o habiendo sido anteriormente Secretario de Estado en el Vaticano sino de un hombre, con real formación teológica, pero de carácter sencillo, pastoral, y con un talante paternal, casi más propio de un párroco italiano que de una figura de repercusión mundial en su inicio. Esa figura fue Juan XXIII y su gesta suprema la convocatoria en 1959 de un Concilio ecuménico en el Vaticano (1962-1965), hecho máximo de la Iglesia en el siglo XX, llevado a cabo bajo el impulso de Pablo VI, y siendo luego determinante de su evolución posterior.

Esa ruptura o abertura a nuevos horizontes, yendo más allá de Italia, comienza a la muerte de Pablo VI (1978) con la elección de su sucesor, yendo más allá del cerco inmediato de la historia pontificia de los últimos siglos y eligiendo un papa no italiano. El último no italiano había sido Adriano VI de Utrech (1522-1523), educador de Carlos V y presente en la política española. Anteriormente desde el Concilio de Constanza (1414-1418), todos habían sido italianos. El último no italiano, junto a otros dos pretendientes a la sede romana, había sido el español Pedro de Luna, fundador de la Universidad de Salamanca, con el nombre de Benedicto XII. Historia de un pontificado afectada por los percances de unos Estados Pontificios, y de un papa rey de este mundo a la vez que sucesor de San Pedro, situación que solo finaliza con Pío XI en 1929 mediante los pactos de Letrán.

La elección de Karol Wojtyla el 16 de noviembre de 1978 es el inicio de una nueva fase en la historia de la iglesia. La elección de J. Ratzinger va más allá de la figura convencional del Papa en momentos anteriores,

\footnotetext{
1 El presente texto pertenece a la intervención del autor en la Real Academia de Ciencias Morales y Políticas (España), Sesión del día 14 de enero de 2014. Aquí aparece con modificaciones.
} 
al elegir a un teólogo profesional, algo que no había sido frecuente después del medievo, ya que siempre se había elegido papa al cardenal de una sede importante, al general de una Orden religiosa o a un canonista. Esta voluntad de ir más allá en orden a una integración de toda la iglesia en la dirección de su vida se consuma en el más allá de Europa con la elección del cardenal de la diócesis quizá geográficamente más lejana de Roma: Bergoglio arzobispo de Buenos Aires.

\section{Dos hechos decisivos inmutadores de una historia secular}

En los últimos diez años hemos sido testigos presenciales, en imagen y en sonido directo, de dos hechos trascendentales en primer lugar para la historia de la iglesia y de manera indirecta para la propia historia de la humanidad, rompiendo una tradición, que parecía haber normativa y en cualquier caso era la costumbre de siglos: la renuncia a la sede pontificia y la elección de alguien localmente tan lejano y anteriormente ajeno al gobierno central de la iglesia.

\section{La renuncia de Benedicto XVI}

Respecto de esta nos preguntamos primero por el hecho mismo, luego por sus motivaciones y finalmente por su repercusión.

a) El hecho. El hecho visto en perspectiva de siglos es un novum absoluto. Dejamos de lado situaciones límite en la vida de la iglesia como fueron los momentos del cisma de Occidente en el que a veces había tres papas simultáneamente y como resultado de los acuerdos o decisiones uno o dos de ellos dimitieron. En tiempos de paz, bien es verdad que en una situación convulsa, solo tenemos un caso: el de Celestino V, elegido tras 26 meses de sede vacante y que solo rigió la iglesia del 5 de julio al 13 de diciembre de 1294.

Su elección tuvo lugar en un contexto de luchas y partidos movidos por esperanzas utópicas de reforma de la iglesia y de sueños milenaristas, en medio de los cuales se eligió a un monje de vida eremítica en los Abruzos, sin apenas formación teológica, que no sabía latín (por primera vez se tiene que usar la lengua vulgar en la corte pontificia) y sin capacidad ninguna para el gobierno. La renuncia era inevitable. ¿Fue el suyo un gesto de humildad o de cobardía? Los años siguientes a esa renuncia fueron de luchas entre los grupos que consideraban inválida la renuncia y quienes considerándola no sólo válida sino necesaria apoyaron a su sucesor Bonifacio VIII. Dante, exponente de esa ilusión reformista y 
milenarista prolongadora de los sueños surgidos en torno a San Francisco de Asís y propalados por Joaquín de Fiore con los grupos franciscanos radicales, le sitúa dentro del infierno en el famoso verso: «Poscia ch'io v'ebbi alcun ricognosciuto Vidi e conobbi l'ombra di colui Che fece per viltà il gran rifiuto» ${ }^{2}$.

La renuncia de Ratzinger, por el contrario, ha tenido lugar con la forma jurídicamente prevista en el Código de Derecho canónico ${ }^{3}$, en situación de normalidad eclesial, como fruto de una decisión tomada con plena libertad y realizada mediante una expresión pública ante el colegio de Cardenales, con un texto pronunciado en latín, en el que se explicitan las razones de esa renuncia: la incapacidad física y espiritual de poder cumplir la misión que el ministerio petrino lleva consigo. Estas son sus palabras pronunciadas el lunes 11 de Febrero a las 11 de la mañana:

Tras examinar ante Dios reiteradamente mi conciencia he llegado a la certeza de que, por la edad avanzada, ya no tengo fuerzas para ejercer adecuadamente el ministerio petrino. En el mundo de hoy, sujeto a rápidas trasformaciones y sacudido por cuestiones de gran relieve para la vida de la fe, para gobernar la barca de San Pedro y anunciar el evangelio, es necesario el vigor tanto del cuerpo como del espíritu, vigor que en los últimos meses, ha disminuido en mí de tal forma que he de reconocer mi incapacidad para ejercer bien el ministerio que me fue encomendado. Siendo bien consciente de la seriedad de este acto, con plena libertad, declaro que renuncio al ministerio de obispo de Roma, sucesor de San Pedro.

Renuncia, por tanto, realizada con plena normalidad jurídica y eclesial por un lado, con libertad personal del interesado por otro.

b) Las motivaciones. Las motivaciones son trasparentes: conciencia de responsabilidad ante el cargo, primacía del deber objetivo sobre la persona que lo ejerce y que se debe plegar a su servicio, edad y con ella la falta de vigor para responder a él, aceptación de los hechos y confianza en la ordenación jurídica de la iglesia que tiene prevista tal situación y anuncio del tiempo intermedio con el fin de preparar todo lo necesario

2 «Después de haber conocido a algunos/miré más fijamente y vi la sombra de aquel/que por cobardía hizo la gran renuncia», Dante, Infierno III, 59-60.

3 «Si el Romano Pontífice renunciase a su oficio, se requiere para la validez que la renuncia sea libre y se manifieste formalmente, pero no que sea aceptada por nadie». Código de Derecho Canónico de 1983. Canon 332, párrafo 2. El mimo Código en su edición de 1917 también contaba con esta renuncia: «Si aconteciere que el Romano Pontífice renunciase, no es necesaria para la validez de su renuncia la aceptación de los cardenales o de otro alguno». Canon 221. 
para la elección del sucesor. Otras hipótesis propuestas para interpretar esta renuncia como las amenazas a su vida, el rechazo de la Curia o la incapacidad para resolver ciertos problemas, carecen de fundamento verificable, aunque ciertas dificultades en estos órdenes hayan colaborado de alguna manera a esa decisión final. La novedad del hecho y el recuerdo de los años finales de Juan Pablo II, quien había mostrado su voluntad de permanecer fiel a su misión en medio del dolor y de la enfermedad hasta el final, llevaron a ciertos grupos a manifestar un juicio negativo respecto de la renuncia, interpretándola como una cobardía. Estas personas y grupos formulan así su juicio: «A un papa, por ser vicario de Cristo, no le es legítimo bajarse de la cruz, ya que debe imitar a quien gusto el vinagre de la crucifixión hasta expirar en ella». Se revivía ahora la doble lectura que se hizo del final de Juan Pablo II: ¿Fue el suyo un gesto heroico o fue más bien la mostración impudorosa ante el mundo de un anciano agonizante, que mantuvo a la iglesia en suspense, y dejó el gobierno de ésta en manos de una guardia pretoriana? Personalmente hubiera preferido otro final en el caso de Juan Pablo II. En cambio, el acto de Benedicto XVI lo interpreté con estas palabras, que puse como título de la página Tercera de ABC publicada al día siguiente: «Responsabilidad, bumildad, grandeza»».

Benedicto XVI renuncia a un cargo al que nunca había aspirado, que solo había asumido por obediencia a la voluntad de Dios al reconocerla manifestada por la elección de los cardenales. Su vida fue una renuncia sucesiva a la propia voluntad, dejándose llevar por la de Dios, manifestada en el consejo, súplica o elección de otros. Rogado por Pablo VI renunció a ser profesor de la Universidad para ser arzobispo de Munich; rogado por Juan Pablo II dejó el arzobispado de la capital bávara para ser prefecto de la Congregación para la doctrina de la fe con acuerdo de poder volver pronto a Alemania, vuelta que se le hizo moralmente imposible tras el atentado del papa y su enfermedad; elegido finalmente por los cardenales para ser obispo de Roma se cerró toda ilusión de volver a ser profesor y de escribir lo que consideraba irrenunciable (Ratzinger, 1997). Esto último se manifestó en el hecho de mantener este propósito escribiendo los tres volúmenes sobre Jesucristo y de cumplirlo aun siendo papa (Ratzinger, 2007; 2011; 2012).

c) Más allá de la sorpresa y reacción inmediata queda la pregunta por la repercusión de largo alcance de esta renuncia. Siendo en principio solo un acto personal, que se respeta aun cuando quizá no se comparta, sin embargo este gesto, realizado en tales circunstancias, adquirió un valor moral constituyente que afecta a las personas más allá de ellas mismas, remitiéndolas a las exigencias objetivas del cargo. Equivalía a decir: en la 
iglesia prevalecen las realidades y responsabilidades objetivas sobre las exigencias o situaciones de las personas. El máximo poder moral se acredita en la máxima obediencia a sus exigencias internas. Queda, sin embargo, abierta la pregunta: ¿Cómo se acredita la mayor fidelidad al cargo: asumiendo sus exigencias hasta el final aun con la pasión y muerte por medio o confiando en la capacidad objetiva de la institución, más allá de los propios sujetos?

\section{La elección de Francisco}

La renuncia de Benedicto XVI constituye el trasfondo inevitable del sentido tanto de la elección (miércoles 13 de marzo 2013) como de la forma de ejercicio del pontificado de Francisco. Nos preguntamos ahora igualmente por el hecho, las motivaciones y la repercusión.

a) El hecho. El hecho de la elección es manifiesto, pero nos quedan desconocidas la forma concreta y las votaciones con la preparación correspondiente que llevaron a este resultado en tan corto plazo. No sabemos a ciencia cierta si ya había sido candidato en la elección anterior, ni de donde procedió la aparición de su nombre, ni qué grupos fueron los decisivos por valoración de él o por exclusión de otros candidatos que fueron apareciendo en las fases previas al conclave. ¿Es verdad que en la elección anterior fue ya candidato y mostró su rechazo cuando le apareció posible su elección? ¿Era él el hombre de otro cardenal jesuita Martini, arzobispo de Milán, que por razones de salud no podía aceptar y que le propuso a él? ¿Orientó Martini hacia Ratzinger cuando Bergoglio rechazó y por tanto quedaba en puerta para la siguiente elección lo que explica la corta duración del conclave?

b) Las motivaciones. Respecto de las motivaciones tanto de los electores como las de él al aceptar, no es fácil imaginarlas. En primer lugar las dos elecciones anteriores habían abierto el horizonte hacia toda la iglesia de forma que ya cualquier nombre, más allá de continente, cultura o lengua, era posible candidato. Sin duda pesaron la voluntad de salir de una Europa con tantos problemas y sobre todo con una especie de cansancio de la fe, de cierta pérdida de la confianza en sí misma, junto con la voluntad de ir desde el centro a la periferia, de las bellas pero estériles teorías ejercitadas en Occidente, a la experiencia de las iglesias jóvenes que han mostrado gran vitalidad en los últimos decenios; quizá también la mirada a una América hispano-lusa que tiene el mayor número de católicos del mundo; finalmente el protagonismo que Bergoglio tuvo en la última reunión del CELAM (Consejo del 
episcopado latinoamericano) (Mayo 2007), reunido en Aparecida (Brasil), siendo el encargado de la redacción del texto final ${ }^{4}$. En él se veía un hombre que había vivido situaciones nuevas y arriesgadas tanto en la vida interna de la iglesia (su crítica situación dentro de la Compañía de Jesús teniendo la autoridad de provincial en ella primero, siendo marginado luego, y situándose él mismo a distancia de ella cuando fue obispo), como en la situación social de un continente convulso por las alteraciones políticas violentas, y no en último lugar su protagonismo en la experiencia nacional argentina.

c) La recepción. ¿Cuál ha sido la recepción y repercusión de su elección? En primer lugar fue de sorpresa por su novedad, al no ser el tipo de candidato imaginado o esperado. Era alguien que venía, dijo el mismo, del fin del mundo. Esa percepción de que los lejanos, los marginados, los que no contaban en el centro del poder mundial, tanto político como religioso, llegaban al centro, se hacían presente en él y con ellos el reverso de la historia, lo no asumido ni aceptado hasta ahora: eso está, sin duda, debajo del entusiasmo casi universal con que ha sido recibido. Ha suscitado un gozo unánime, un entusiasmo concorde y una esperanza a primera vista excesiva, dado el desconocimiento de su personalidad, y motivada casi solo por mínimos gestos y pocas palabras. Todas las esperanzas e ilusiones parecen haberse concentrado en él, como si hubiera llegado el momento de realizar la reforma de la iglesia, el anuncio eficaz del evangelio, la renovación de los cristianos y el cambio en la orientación espiritual del mundo.

Mientras que Ratzinger era admirado a distancia pero no muy citado, Bergoglio, en cambio, es ahora una cita permanente en charlas, conferencias y conversaciones. A ello han contribuido su sencillez, inmediatez, inteligibilidad, cercanía personal y un discurso nada teórico sino totalmente concreto, en sintonía con las grandes situaciones negativas de la humanidad: la guerra, el hambre, la inmigración, el tráfico de personas y de órganos humanos entre el tercer mundo y el primero. Novedad en los gestos y en la forma de vida, de lenguaje y de trato directo. Hasta este momento tenemos grandes gestos y promesas por un lado; grandes esperanzas y confianza por otro. Ahora debe llegar el tiempo de corresponder a las expectativas y de llevar a cabo las promesas, para que no sobrevengan luego las grandes desilusiones, distancias y rechazos.

\footnotetext{
$4 \quad$ V Conferencia general del episcopado latinoamericano y del Caribe, Documento conclusivo: Discipulos y misioneros de Jesucristo para que nuestros pueblos en Él tengan vida "Yo soy el camino, la verdad y la vida” (Jn 16,4), Aparecida 2007.
} 
El diagnóstico que hace la revista Herder Korrespondenz (12-2013, pág. 595) para su recepción en Alemania me parece que vale también para países como el nuestro:

El 'cambio de curso' que se les quiere presentar a los obispos alemanes como doctrina y ejemplo de vida (imitando las de Francisco), es por el momento todavía un fenómeno bastante oscilante (scbillernd), una mezcla de imprevisibles indicios, esperanzas y esperas pero también de muchas deseos propios proyectados sobre él.

Hay una alegría y entusiasmo generalizados, pero con tres matizaciones importantes: una primera postura es de espera con cierta perplejidad (para decirlo con una nomenclatura impropia, sería la propia de una actitud de centro); una segunda postura es de malestar por considerar la actitud de Francisco falta de seriedad, de respeto y de aquella compostura externa que corresponde a las grandes realidades internas y signos sagrados, mientras cede a fáciles y ambiguas posturas cercanas al populismo (sería la postura de derechas); una tercera postura es de escepticismo y de rechazo para la cual todo esta novedad es un superficial lavado de la fachada, mientras que todo lo esencial del pontificado, de Roma y de la iglesia católica sigue igual (sería la postura de la izquierda radical).

\section{Una misma misión para dos personas y dos destinos}

\section{La realidad del ministerio petrino}

El ministerio petrino tiene una estructura interna, una lógica propia, anterior y superior a quien la asuma y a la que tiene que amoldarse, como se adecua el pie a la horma del zapato. No está por inventarse porque está ya inventado y ha sido ejercitado durante siglos por más de trescientos sucesores de San Pedro. Si de esta reflexión se concluye que el ministerio petrino debe configurar al sujeto que lo ejerce, no menos verdad es que dicho ministerio tiene una plasticidad y flexibilidad grandes de forma que se puede decir con igual verdad que la persona configura el ejercicio del ministerio y en este caso de forma máxima, ya que es la autoridad suprema y universal respecto de la realidad eclesiástica sobre la que se ejerce y sobre las personas, con el único límite de la revelación originaria y de la tradición apostólica y eclesial normativas: el ius divinum derivado de dos principios: uno, el origen en Cristo, y otro: la acción conjugada del Espíritu Santo y de los apóstoles 
en los momento supremos de decisión eclesial, es decir en los Concilios ecuménicos.

\section{Tres configuraciones históricas diversas}

En este sentido la segunda mitad del siglo XX nos ha ofrecido tres configuraciones del pontificado troqueladas muy particularmente por el destino anterior y por la psicología particular de sus exponentes.

a) Juan Pablo II. El primero de estos tres es Wojtyla viniendo de una situación política e ideológica como la de Polonia en la que las dos grandes ideologías totalitarias del siglo XX, comunismo y nazismo, se habían propuesto destruir o marginar el cristianismo y donde iglesia tuvo que afirmarse en medio de apuestas martiriales. De ahí su permanente reclamación de la libertad política y religiosa, del respeto a la dignidad del hombre, de los derechos humanos, de la posibilidad y necesidad de creer para todos, pobres o ricos, intelectuales o pueblo, en un ejercicio gozoso y casi lúdico de la fe. Fe que había sido vivida en Polonia como una potencia de dignificación de cada sujeto, de fortaleza y resistencia frente a los máximos poderes de este mundo. La fe era así vista y propuesta como la evidencia y necesidad supremas, como algo profundo y sagrado para el hombre más allá de la filosofía, de la riqueza, de la política y de las situaciones concretas. Fe que había sido liberadora para un pueblo frente a un inmenso poder político como el Estado soviético; fe sin las dudas y perplejidades propias de un Occidente libre y rico, olvidado de la tragedia padecida por millones de personas bajo el nazismo y comunismo durante el medio siglo anterior, en tiempo de guerra abierta y de paz encubierta.

b) Benedicto XVI. Ratzinger, en cambio, es un alemán, catedrático de universidad, forjado en el diálogo con la Ilustración y la razón crítica de la modernidad, en reflexión permanente con los críticos de la religión en el espacio abierto de la sociedad. Los permanentes dialogantes implícitos a los que se dirige son los que Ricoeur designó como «maestros de la sospecha», para los que el creer como tal, la fe dogmática y la iglesia institución, son falsas o se han vuelto problemáticas, tanto en sus contenidos como en sus fundamentos. En el fondo está dialogando siempre con las minorías pensantes y dirigentes; minorías desde las que en la historia anterior han pasado a la masa las convicciones que hoy la determinan. Si el grito «Dios ha muerto», proferido por Nietzsche (El Gay saber, párrafo 125) a finales del siglo XIX, a comienzos del siglo XX era solo la casi oculta y minoritaria convicción de unos pocos, a comienzos del siglo XXI se ha extendido como una mancha de aceite a 
amplias capas de la humanidad. Esa proclamada o reclamada muerte de Dios ha arrastrado consigo el orden de valores suprasensibles como son el ser, la verdad, el deber, el sentido, la esperanza y el futuro. Con la transvaloración de los valores anteriores mueren o quedan en vilo no sólo la religión sino también la moral, el derecho, la democracia, el pluralismo, los derechos humanos; en una palabra, los suelos y techos de la casa en la que habían habitado hasta ahora los hombres en esa Europa, que quedó sumida en el fuego destructor de dos guerras mundiales y de dos mortíferas ideologías, para concluir en un final de siglo XX que no ofrece ningún proyecto ético a la humanidad, ahora resentida y desilusionada ante el fracaso de muchos ideales propuestos por la ideología del progreso. Se ha pasado así del entusiasmo de la modernidad a la nostalgia y desilusión de la posmodernidad.

Sobre ese fondo de cultura Ratzinger se preguntó: Ante tal situación de la conciencia humana en Europa, ¿cuál es la aportación específica de la iglesia a este mundo en el orden de la verdad, del sentido, de la responsabilidad, de la libertad y de la esperanza, partiendo de la convicción presupuesta de que para otros órdenes de necesidad la sociedad y la ciencia tienen ya recursos e instrumentos suficientes para subvenir a ella? Estas son las preguntas fundamentales de Ratzinger: En un mundo donde se apaga la luz de Dios, ¿permanece entera y encendida la luz del hombre? ¿Dónde se engendran los proyectos que deciden el destino de la humanidad: en los laboratorios que producen ciencia, en las universidades que deben ser fuentes de sabiduría, en los parlamentos que gestan legislación, en los templos donde el hombre se abre a Dios en oración y alabanza, en la acción social y política? Y si cada uno de ellos crea su parte de verdad, ¿qué relación hay entre cada una de esas creaciones para el destino final y para el último sentido de la vida humana, es decir para la salvación?

Desde esta comprensión de nuestro presente histórico propia de quien, más allá de la espuma del mar que ve, adivina las corrientes profundas e invisibles que empujan el oleaje, desde ahí ha pensado, ha hablado y ha sido papa Ratzinger, intentando desvelar, junto con los presupuestos explícitos, las convicciones implícitas y los poderes que determinan hoy la vida humana: la personal y la social, la política y la religiosa. Él está convencido de que tanto la razón como la religión, siendo ambas esenciales a la vida humana, pueden volverse locas y de que solo la abertura, colaboración y crítica recíprocas mantendrán sensato, justo y esperanzado el mundo. Ratzinger ha sido un hombre de pensamiento más que de acción, consciente del valor de la fe para la vida humana en todos los órdenes, preocupado por la responsabilidad moral, social y política tanto del cristianismo, con su propuesta de verdad y 
sentido trascendentales, como de la iglesia en cuanto comunidad de fe, de testimonio y de acción en medio de la sociedad. Ratzinger se ha preocupado de la situación espiritual y moral del mundo, no solo de la iglesia católica; del sentido y fundamentación del derecho, de la ética y de la política; por tanto, no solo de la legitimación de la religión, del dogma y de la teología. Él es de los que piensan que son las ideas las que siguen rigiendo el mundo.

En el fondo él se ha seguido comprendiendo a sí mismo como prolongando en un nivel nuevo su misión de profesor de Universidad al que ahora se le ha dado una cátedra mucho más amplia y exigente, con el cristianismo (historia, doctrina, vida) como asignatura, y con el mundo como auditorio. Ante éste sabía que tenía que afrontar con rigor la cuestión de si este cristianismo concreto es la verdad de la vida humana, o su desfiguración y alienación (Marx); si su doctrina teológica es la proyección ingenua de una antropología (Feuerbach); si su moral nace del resentimiento y su ascética del miedo ante este mundo (Nietzsche). Para él Dios es la palabra que más ha dado que pensar, que actuar, que imaginar y que esperar. Tarea esencial, por tanto, es la de pensar para creer y de creer para pensar hasta el fondo.

Si algo ha hecho la fe cristiana a lo largo de sus veinte siglos ha sido dar que pensar, aun cuando a veces se haya pervertido a sí misma reprimiendo el pensamiento o negando la libertad para ejercerlo, pero en medio de todos esos empeños y desvaríos ha mantenido encendida la llama del evangelio y viva la memoria de la persona de Cristo. Esos rumores profundos y estas posibilidades para la vida humana han guiado la palabra y la acción de Benedicto XVI, en cierta distancia a la política eclesial inmediata, y en un ejercicio de gobierno que en ciertos momentos hubiera debido ser más intenso y directo. ¿Cuáles deben ser la jerarquización y la proporción entre las tres tareas sagradas de un papa teniendo que ser a la vez, padre, pastor y maestro? ¿A quién debe dirigirse hoy ante todo: a los de dentro o a los de fuera, a todo el rebaño o a la oveja perdida, a los creyentes o a los increyentes, a los medio fieles o a los del todo infieles, a los perplejos cercanos o a los lejanos que ni siquiera están perplejos?

b) Francisco. En la configuración del ministerio petrino por Bergoglio es en la que quizá aparece más patente la ruptura. Su persona y destino surgieron, cuajaron y han llegado a sus 76 años en un mundo bien distinto del de Europa, si bien culturalmente sea el mismo. Él es un argentino de Buenos Aires, porteño. En una Sudamérica agitada política y teológicamente, por intelectuales y guerrillas, durante los últimos cincuenta años, donde se han sucedido revoluciones políticas con 
intentos revolucionarios, unas veces desde las cúpulas militares y otras desde el pueblo como en Chile, Colombia, Argentina, Bolivia, Uruguay, Venezuela. En ese marco, personas y grupos de iglesia han jugado un papel clave con la palabra o con el silencio y no siempre en la misma dirección política: desde la propuesta de una teología de la revolución y de la liberación hasta el silencio, connivencia o benevolencia con los regímenes militares.

Argentina ha sido el epicentro de tres terremotos de gran intensidad. Uno, los grupos políticos de guerrillas (los Montoneros, y en su cercanía, material en uso casos e ideológica en otros, los Sacerdotes para el tercer mundo); otro los regímenes militares que surgen con la clara voluntad de aniquilar a los anteriores, cuando se ha puesto en marcha desde Estados Unidos la Operación Cóndor que une a casi todos los países del cono sur en la lucha a muerte contra los movimientos socializadores, tachados de marxistas y comunistas; y el tercero es la fractura dentro de la Compañía de Jesús en Argentina, con el vuelco dado a su orientación al final del Concilio Vaticano II, que supuso una gran pérdida de vocaciones para entrar y de salida o secularización de no pocos profesos, que eligieron la acción política directa por la integración en las guerrillas en algunos casos y por la animación indirecta en otros. Una gran parte de ellos fueron a los lugares de la marginación y del conflicto, con propuestas políticas concretas, asumiendo responsabilidades gubernativas como Arroyo en Chile, ministro de agricultura en el gobierno de Allende o Fernando Cardenal en el gobierno de los sandinistas en Nicaragua. Ese triple contexto afecta la configuración de la personalidad de Bergoglio, que es provincial en el periodo crítico de 1970-1980. El 20 de mayo de 1992 es nombrado por Juan Pablo II obispo auxiliar del cardenal A. Quarrachino de Buenos Aires y el 3 de junio de 1997 coadjutor con derecho de sucesión y después como arzobispo de Buenos Aires. Es el momento en el que el peronismo sigue manteniendo a Argentina en una línea de fantasías populistas, sin acabar de asumir una modernización política, económica y financiera, similar por ejemplo a la de Chile, y sobre todo sin superar una corrupción generalizada. De entonces viene su enfrentamiento con los Kirchner.

De ese trasiego de tensiones inevitables bajo un régimen militar teniendo que aceptar por un lado los movimientos socializadores que reclamaban justicia social y por otro lado tener que rechazar los planteamientos teológicos, teniendo que reconocer los hechos en los que estaban insertos personas y grupos de iglesia; con el apoyo a los miembros de la Compañía y su distancia a ciertos planteamientos religiosos de algunos de ellos: esa es la matriz de la compleja personalidad de Bergoglio. De su historia quedan muchos hechos, cuyo 
contenido y motivaciones tanto dentro de la compañía de Jesús como fuera de ella no conocemos, porque no tenemos todavía información críticamente verificada.

De esa historia mantiene Bergoglio el siguiente legado: La teología de la liberación, pero no la que elige la mediación política directa para hacer presente y eficaz el evangelio sino la que eligió como mediación privilegiada la cultura, la ética y la religión popular de unas masas que tienen a ambas como su gran tesoro y no deben ser expoliadas de ellas en función de una hipotética liberación política. De ahí su apoyo a teólogos como el sacerdote Lucio Gera y el jesuita Scanone que fueron los animadores de la iglesia argentina en esa dirección ${ }^{5}$. Al mismo tiempo su distancia frente a la línea de inmersión social-política prevalente en la Compañía de Jesús a la que se le había consentido benevolencia en los generalatos de Arrupe y Kolvenbach. Con este último entró Bergoglio en conflicto y de ahí provino su alejamiento en Alemania y su marginación en la Compañía. El decenio 1980- 1990 es de distancia y de silencio. Ya arzobispo y cardenal de Buenos Aires encontró la distancia y reserva de algún sector de la Curia tardando más de un año en la aceptación del profesor Víctor M. Fernández, a quien él había propuesto como rector de la Universidad católica, y al que al poco de ser papa nombró arzobispo.

De Buenos Aires se trajo por un lado la libertad, la confrontación sutil y la distancia crítica frente a unos políticos corruptos y falsificadores de la información sobre la realidad social. Luego la experiencia de la marginación, pobreza, secuestro y utilización de las masas en los suburbios, que considera como consecuencia de unos sistemas económicos que las marginan, utilizan y a la larga mantienen en una pobreza creciente. De esa experiencia le manan un lenguaje que puede

5 La valoración y aprecio que Bergoglio tenía para esta línea de pensamiento liberador desde la cultura y la misericordia se puso de relieve en su decisión de enterrar en la Catedral de Buenos Aires al exponente más significativo de ella, Lucio Gera, con una inscripción sepulcral que le designa padre de la iglesia en Argentina. No enumeramos las fuentes de la formación teológica de Bergoglio y sus años de enseñanza en las Facultades de Filosofía y Teología S.J. de San Miguel (Buenos Aires), de las que fue rector, antes de que las desligaran de la Compañía En la revista de estas Stromata publicó una serie de artículos. En ellos se remite a dos grandes teólogos europeos: H. de Lubac y H. Urs von Balthasar, a la vez que a los textos de Juan Pablo II. También a los documentos del CELAM en sus reuniones de Medellín (1968) y Puebla (1979). Todo esto le hace cercano en un sentido y lejano en otro a la Teología de Liberación, tal como ella aparece en G. Gutiérrez, L. Boff, I. Ellacuría y J. Sobrino. Cf. López Cambronero \& Merino Escalera, 2013. Aquí se puede encontrar un apéndice documental, referido sobre todo a la convulsión político-social de Sudamérica en esos años y a la relación de Bergoglio con los regímenes militares. 
sonar a grito de libertad o a populismo, una voluntad de cambio, de simplificación, de protesta y de rechazo de muchas actitudes, realidades e instituciones consideradas hasta ahora como evidentes y normales. ¿Dónde está la línea divisoria entre un clamor ético y una voz profética que son sagrados y que pertenecen a la entraña de la iglesia por un lado y por otro un populismo que no diferencia suficientemente la función utópica de la religión, de la función propia de una política como gestión eficaz de lo único posible en cada lugar y tiempo; que no identifica los objetivos últimos y los inmediatos, los fines y los medios, las metas utópicas y las únicas realizaciones históricas, que sean posibles en cada lugar o situación nacional?

\section{Dos proyectos diferenciados para la misma iglesia}

Cada hombre puesto ante una misión actúa desde tres instancias: 1) Desde la forma en que él percibe su deber respondiendo a las exigencias objetivas de la misión. 2) Desde la consciencia de sus propias capacidades y la valoración de su adecuación a dicha tarea. 3) Desde el enjuiciamiento que haga de la situación concreta de la realidad histórica y de las condiciones concretas en las que se halla la institución que tiene que dirigir, en nuestro caso la sociedad contemporánea y la iglesia, tanto en sí misma como en su relación con aquella. La primera instancia es manifiesta a quien ha aceptado la elección de los cardenales para ser obispo de Roma y en calidad de tal cabeza visible y autoridad máxima de la iglesia católica, a la que representa de forma no única pero primordial ante el mundo. Decisiva es también la propia personalidad en un sentido y la forma concreta en la que cada uno piensa que la iglesia debe cumplir su misión en un tiempo concreto. Luego viene en tercer lugar la peculiar experiencia de iglesia que traiga y la valoración que haga de la situación en que ésta se halla y de su relación con la sociedad.

Y referidas a este tercer punto (situación de la iglesia) surgen preguntas como las siguientes. En clave negativa primero: ¿Cuáles son sus mayores necesidades, carencias, vacíos, tentaciones, pecados? ¿A cuál de estos ámbitos debe ante todo dirigir su atención? Y en el orden positivo: ¿Cuáles son las personas, instituciones, movimientos u otras formas tanto de vida como de acción que son los más aptos para cumplir la misión de la iglesia y, por ello, deben ser promovidos, apoyados y defendidos con predilección? ¿Qué es más urgente: el fortalecimiento, reestructuración y reforma de la iglesia (fe, teología, instituciones, personas) o una dinamización de la iglesia en el encuentro, diálogo y colaboración con los de fuera? ¿Se puede llevar a cabo esto sin aquello? 
Por consiguiente: ¿qué debe obtener primacía: la identidad y perforación hacia adentro o la función hacia fuera, la institución o la misión, la mística o la política? Si la alternativa no puede ser llevada nunca hasta las últimas consecuencias absolutizando una frente a la otra, ¿en qué relación son de hecho vividas hoy y a cuales debemos atender más, por estar más desvalidas teóricamente o más descuidadas prácticamente?

\section{La propuesta de Pablo VI: «Iglesia hacia adentro-Iglesia hacia fuera»}

Pablo VI propuso al Concilio Vaticano II dirigir una doble mirada a la iglesia como hecho y como misterio: "Ecclesia ad intra-Ecclesia ad extra». A esa doble mirada corresponden los diversos documentos conciliares. Tres Constituciones acentúan la mirada a la perspectiva interior o las fuentes e instancias internas de la iglesia: La Liturgia (Sacrosanctum Concilium), la Biblia (Dei Verbum), la propia realidad sobrenatural e histórica de la iglesia (Lumen gentium). Una cuarta Constitución, mirando al mundo con los ojos de la inteligencia analítica y con los de la fe, propone desde ese análisis las relaciones de reciprocidad que tienen que regir entre la sociedad y la iglesia (Gaudium et Spes). El hombre, la historia, la sociedad están en el primer plano de interés en esta Constitución, que comienza mostrando la voluntad de la iglesia por compartir los gozos y las esperanzas de los hombres. ¿Cuál de esas dos miradas de la iglesia se debe cultivar con especial interés hoy? ¿Cuál ha sido más desatendida en los últimos decenios y, por consiguiente, es más urgente? De la respuesta que cada Papa da a estas preguntas depende el ejercicio de su pontificado. Cualquiera que sea esa respuesta resultará limitada y parcial, en primer lugar porque ninguno puede abarcar con plenitud todas las funciones de su ministerio, y en segundo lugar porque son muy distintos primero los problemas que tiene que iluminar y luego las necesidades tanto de cada uno de los continentes como de los sectores a los que debe dirigirse.

\section{Programa de Benedicto XVI a la luz de su primera encíclica Deus caritas est. La preocupación doctrinal en el centro. La fe.}

Si ahora tuviéramos que adivinar cuál ha sido la respuesta, no teórica sino práctica, que cada uno de estos dos papas ha dado sobre lo que es más grave objetivamente y más urgente hoy, diríamos lo siguiente. Para Ratzinger lo que está sobre todo en juego poniendo a la humanidad en el borde es la posibilidad y conveniencia de la fe en Dios y la amenaza a lo humano que la pérdida de esa fe implicaría. De ahí deriva la tarea 
esencial de la iglesia, la que le es específica, la que ninguna instancia de este mundo puede ni se propone cumplir: ser altavoz, testigo, vigía, defensora y cultivadora permanente de la conciencia de lo divino en el hombre y de la revelación de Dios en la historia. No solo afirmar la existencia de Dios sino introducir al encuentro con él, animar la relación orante y contemplativa, iluminar la forma de vida resultante de esa relación, diferenciarle de los ídolos. Importante es mostrar que Dios existe pero sobre todo qué Dios existe, quién es, cuál es su comportamiento con los humanos, qué espera y qué exige de ellos; qué ídolos le suplantan en cada momento a los que hay que desenmascarar y derribar.

Ratzinger aborda esta tarea de fondo en cada una de sus tres encíclicas, en diálogo con los grandes movimientos espirituales y sociales de la modernidad. Su primera encíclica (la que siempre se suele considerar caracterizadora y programática de cada Papa) lleva por título: Deus caritas est $=$ Dios es amor-caridad (25 diciembre 2005). Comienza diferenciando la fe de la filosofía, de la ética y de las ideologías, con una referencia y respuesta a Nietzsche, quien afirmó que el cristianismo había envenenado el placer, contraponiendo el amor humano y el amor divino, y al separar radicalmente el eros y el agape ${ }^{6}$. La segunda encíclica: Spe salvi $=$ Salvados en esperanza (30 noviembre 2007) se pregunta por la relación entre las esperanzas accesibles a nuestras posibilidades de hombres y la esperanza teologal, es decir entre el reino que los hombres podemos construir y el Reino que tiene a Dios como contenido y autor, que es nuestro Futuro absoluto y solo posible como fruto de gracia. Es un diálogo permanente aun cuando implícito con Marx y Ernst Bloch. La tercera encíclica Caritas in veritate $=\mathrm{La}$ caridad en la verdad $(29$ junio 2009), la menos personal, prolonga la reflexión anterior e intenta mostrar la conexión interna entre ortopraxis y ortodoxia, y por ello la necesaria relación histórica, entre caridad y verdad, entre justicia y misericordia.

Para descubrir las grandes preocupaciones de este Papa hay que referirse también a sus tres discursos en las Universidades de Ratisbona, la Sapienza de Roma y los Bernardinos de Paris, donde expone las relaciones entre la fe y la razón, la dimensión pública de la fe y la dimensión religiosa de la razón. Allí analiza también el lugar del cristianismo en la construcción de Europa, y se pregunta por la capacidad o incapacidad que tiene una sociedad para proteger derechos fundamentales cuando no cultiva valores fundamentales, la perduración

\footnotetext{
6 «Das Christentum gab dem Eros Gift zu trinken - er starb zwar nicht aber en tartete zum Laster $=$ El cristianismo dio de beber veneno a Eros - éste ciertamente, no murió, pero degeneró convirtiéndose en vicio» (Nietzsche, 1983: 110).
} 
de una cultura y civilización cuando abandonan los fundamentos sobre los que ellas han surgido, en nuestro caso la perduración de los valores de Occidente sin la fe cristiana que estuvo en su origen. A estos textos habría que añadir sus intervenciones en diálogos como el sostenido con el filósofo alemán J. Habermas y con políticos como el senador italiano M. Pera; junto con sus discursos en los Parlamente alemán e inglés. En estos últimos se plantea el problema de las fuentes morales del derecho y de la democracia, la relación entre derecho, ética y religión, la posibilidad o imposibilidad de responder a todas las necesidades del hombre, cuando se excluye la mirada a la trascendencia, a Dios (González de Cardedal, 2003).

Detrás de estas intervenciones en lugares creadores de sentido en la sociedad europea está su convicción de la responsabilidad e influencia de Europa en el resto del mundo. Reconoce su grandeza técnica y sus conquistas espirituales, pero a la vez le los 150 millones de víctimas provocadas por las dos guerras mundiales, como resultado de una negación de Dios, único soberano del hombre, y de la absolutización de los ídolos, fueren éstos la raza, el pueblo, la nación, las personas o las ideologías, que elevaron una comprensión del hombre y de la política a criterio legitimador de toda acción. A la vez Ratzinger mira perplejo a una Europa que olvida, niega o vuelve las espaldas a su historia cristiana, que mantiene un silencio oficial sobre Dios, que no logra encontrar un lugar pacífico para las religiones en su ordenamiento jurídico, que está terminando escindida entre una comprensión absolutamente desacralizada de la existencia y un fundamentalismo violento, posturas que se excluyen en raíz y que, sin embargo, se están sosteniendo por contraste una a otra (González de Cardedal, 2014).

\section{Continuidad o discontinuidad de Francisco}

¿Qué decir ahora del nuevo Papa, de sus actitudes e ideas fundamentales? Existe el hecho público de su voluntad expresa de continuidad a la vez que una real distancia con lo anterior. La continuidad se expresó en la asumpción como suya de la encíclica Lumen fidei, escrita por Benedicto XVI, en la afirmación repetida de que él no va a entrar en las cuestiones ya clarificadas y decididas por su predecesor. Pero aún no tenemos tiempo ni distancia suficiente para comprender y valorar sus actuaciones. ¿Consiste la novedad solo en los gestos, signos, modales exteriores, forma sencilla, directa y comprensiva de hablar? ¿Qué pensar de sus ideas y propósitos de largo alcance para el futuro de la iglesia? Hasta ahora solo tenemos los elementos siguientes para juzgarle: las homilías diarias en la Residencia de Santa Marta, elegida para 
vivir dejando el Palacio apostólico, sus gestos de cercanía a niños y pobres, su viaje relámpago a Lampedusa como forma de alertar al mundo ante el drama de la emigración de los países pobres a la rica Europa, su empeño público por la paz proponiendo 24 horas de oración ante el Santísimo en todo el mundo para evitar una guerra en Siria que de hecho habría sido mundial, su repetida afirmación en favor de lo que él llama las periferias y los marginados de un mundo nuevo en el que el final de la existencia rural ha hacinado millones en las grandes urbes, donde carecen de los medios elementales para una existencia digna: trabajo, salud, educación.

Ante semejantes comportamientos suyos surge la pregunta por sus ideas y los programas que vayan más allá de un moralismo permanente y de una respuesta psicológica y ética, que en el fondo es idéntica a la de todos los demás grupos de la sociedad moralmente preocupados. Algunos de los problemas graves de los existentes en la iglesia le fueron identificados y en parte resueltos por su predecesor: la pederastia, los Legionarios, la situación financiera del IOR, la curia y su trasparencia organizativa. En el orden de la reforma institucional y moral de la Iglesia de largo alcance solo tenemos un par de nombramientos significativos, el de Secretario de Estado y algún otro como los nuevos cardenales y en concreto como el del español Fernando Sebastián. La creación de una comisión de ocho cardenales es solo un cuerpo de consultores suyos, sin integración canónica en el ordenamiento jurídico de la Iglesia; es decir, sus decisiones solo son propuestas para el Papa. Veremos cuáles sean éstas y qué hace él con ellas.

Desde el punto de vista doctrinal tenemos un documento suyo, con el título: La alegría del evangelio, y por subtítulo: Exhortación apostólica (24 noviembre 2013). Esta identificación literaria y doctrinal del documento ya es significativa. De las nueve formas en las que el Papa suele ejercer su magisterio ordinario ésta viene en quinto lugar. La preceden las siguientes: Constitución apostólica, Encíclica, Carta apostólica, Motu propio. Y la siguen estas otras cuatro: Mensajes, Discursos, Homilias, Catequesis. Este documento al que nos referimos es un texto complejo que incluye aspectos heterogéneos: en parte es el documento que sigue al Sínodo de los obispos sobre la nueva evangelización, equivalente al que cada Papa publica como síntesis acogedora de lo que los Padres sinodales han dicho o sugerido que deba hacerse; en parte quiere ser una alocución que clausura el año de la fe, propuesto por su antecesor; y no en último lugar más que su programa de acción es la manifestación de sus intenciones personales, deseos y consejos. En este documento integra textos suyos anteriores. Trata los temas de acuerdo al subtítulo del documento, es decir en tono exhortativo y sugeridor, un poco en la línea interiorizadora 
de los Ejercicios Espirituales. Su tono final es el propio de un profeta, a quien le urgen ante todo la acción, la justicia, la misericordia, la revelación del Dios, que vela por la sangre y la vida de los hombres. Da la impresión de que todo lo demás puede esperar.

He subrayado que se trata de una Exhortación, porque de la índole del documento deriva la autoridad que reclama y el asentimiento que se le debe: no es lo mismo una palabra ex cathedra como proposición de una verdad relativa a la fe o a la moral que una catequesis de los miércoles. El Concilio Vaticano II explicitó los criterios para descubrir la normatividad y adhesión debida a las palabras del Papa:

Este obsequio religioso de la voluntad y del entendimiento ha de ser prestado de modo particular al magisterio del Romano Pontífice aun cuando no hable ex cathedra; de tal manera que se reconozca con reverencia su magisterio supremo y con sinceridad se preste adhesión al parecer expresado por él según su mente y voluntad, que se colige principalmente ya sea por la índole de los documentos, ya sea por la frecuente proposición de la misma doctrina, ya sea por la forma de decirlo (Lumen Gentium, 25).

\section{Programa de Francisco a la luz su primer gran documento: La alegría del evangelio. La preocupación social en el centro. La caridad-misericordia}

Lo que da el tenor al documento es el mismo título: una llamada a la alegría en la iglesia, sostenida no tanto por su valor y virtud propios cuanto por la potencia interna del evangelio que ella lleva entre manos. Esta idea la asume de la Exhortación apostólica de Pablo VI Gaudete in Domino (9 de mayo 1975). Tal alegría es lo determinante de su postura vital. No son el miedo, ni la angustia, ni la preocupación ante las ideologías o potencias de este mundo, los que mueven su actuar sino la confianza y el gozo resultantes de la fuerza inmanente del evangelio, más allá de nuestras posibilidades o necesidades. Ese evangelio es el tesoro y la perla por la cual merece la pena vender todo lo que se tiene para poseerlo $(M t 13,44-46)$. Este título es revelador de lo que es el aliento de las nuevas iglesias o del llamado tercer cristianismo, que se comprende a sí mismo más allá de los integrismos o progresismos europeos. Se trata de las iglesias de los mundos jóvenes, de los países de misión, de las nuevas comunidades y métodos evangelizadores, llámeselos movimientos carismáticos, neocatecumenales, revivalistas...

Frente al silencio de Dios en Europa y a la disminución cuantitativa de la Iglesia en personas e instituciones, estas iglesias crecen con un vigor 
inusitado entre nosotros y con una voluntad misionera de dirección inversa de la vivida hasta ahora. Esas iglesias nuevas están dispuestas a venir a evangelizar a una Europa ya pagana o en camino hacia una noche de la fe. ¿Es este entusiasmo un real comienzo nuevo de la vieja iglesia, como lo hubo en el siglo XIII con los franciscanos y dominicos, en el siglo XVI con los jesuitas y las carmelitas o en el siglo XIX con las innumerables fundaciones de congregaciones religiosas tras las revoluciones? ¿ $\mathrm{O}$ es por el contrario un entusiasmo adolescente que terminará sufriendo las mismas crisis de maduración de la fe y de choque con una razón positivista, funcional e instrumental, tal como la estamos viviendo en Europa, que desafía no solo al cristianismo sino a toda cultura de la trascendencia y de la esperanza absoluta, de la afirmación definitiva del hombre como ser para la vida definitiva y no para la nada final?

El texto de este primer documento de Francisco se dirige a la iglesia en su doble nivel: en cuanto comunidad de fe y en cuanto institución de este mundo. La invita a un despertar y a una conversión misionera (I Parte), a un compromiso comunitario con el mundo (II Parte), a anunciar de nuevo el evangelio como constituyente del pueblo de Dios y su gran tesoro (III Parte), a recuperar la dimensión social de la evangelización (IV Parte). Dentro de este marco general aparecen casi todos los problemas y preocupaciones pastorales de la iglesia. Laten en este texto ecos personales de Juan XXIII (bonhomía, tenor pastoral, piedad, confianza), ecos populares de Juan Pablo II (la actitud del gran actor que subido al tablado de la cátedra de Pedro y se dirige al mundo para escenificar la verdad del evangelio como libreto), a la vez con referencias explícitas a las encíclicas de Pablo VI: a la Ecclesiam suam sobre el diálogo con el mundo como camino de la iglesia (del 6 de agosto 1964) y a su documento postsinodal: Evangelii nuntiandi (del 8 diciembre 1975). Un ejemplo de su voluntad de descentralización de la iglesia es la integración de textos del episcopado mundial y de documentos de las Conferencias episcopales (18 citas) junto con citas de padres de la iglesia, de algunos teólogos y líderes espirituales.

En este documento prevalecen las citas del magisterio pontifico reciente. En primer lugar están las 27 citas tomadas de las Proposiciones elaboradas por el Sínodo de los obispos al final de la XIII Asamblea General Ordinaria, celebrada del 7 al 28 de octubre de 2012, sobre La nueva evangelización para la transmisión de la fe cristiana. La exhortación que los papas publicaban después de dichos sínodos se designaba como «postsinodal», término que, sin embargo, no usa Francisco en este caso. Luego vienen Juan Pablo II (48 citas), Benedicto XVI (22 citas), Pablo VI (21 citas), el Vaticano II (17 citas), Santo Tomás (13) algunos Padres 
de la Iglesia: con 2 citas San Agustín y con 1 el resto (San Ireneo, San Ambrosio, San Cirilo, San Juan Crisóstomo, San Juan de la Cruz), organismos de la Santa Sede como el Consejo Pontificio Justicia y Paz (8 citas), la Congregación para la Doctrina de la fe (4 citas), la Comisión teológica internacional (3 citas), y otras instituciones como la Acción Católica italiana. Siguen con una cita Platón, Tomás de Kempis, Isaac de Stella, Juan Diego, Newman, Teresa de Lisieux, H. de Lubac, I. Quiles, R. Guardini, Bernanos, Víctor M. Fernández. A la luz de estas fuentes uno tiene la inclinación a considerar este documento más que como un texto con autoridad magisterial pontificia, como un escrito similar al de los teólogos o pastoralistas. De otro modo se prolonga aquí la unión pero no la diferenciación introducida ya por Benedicto XVI entre el teólogo que piensa junto con sus colegas y el papa que habla con autoridad. Aquel diferenció, sin embargo, claramente entre sus libros personales y los documentos oficiales.

Si el centro del pensamiento de Ratzinger estaba en Dios, en el cristianismo, en la preocupación por el lugar de la fe en la conciencia crítica que la pone bajo sospecha, en la dificultad o gozo de rezar el Credo con honestidad intelectual por quienes han pasado por la Ilustración y la modernidad, en el pensamiento de Bergoglio se da por supuesto el Credo, que no le crea dificultad alguna, y los dogmas con las realidades tradicionales constituyentes de la iglesia. Yendo más allá de todo ello mira a los hombres concretos en situación y acentúa las obras de misericordia, reclama el testimonio de la caridad, recuerda a la iglesia su obligación de revivir el ejemplo de Jesús buen samaritano para con los hombres caídos levantándolos del suelo y curándolos, sin antes preguntarlos ni exigirles nada, anteponiendo así la acción de la misericordia a los postulados de la moral, a las exigencias del dogma, y a los cánones del Código de derecho canónico, ninguno de los cuales son ocultados pero no son puestos en un primer plano anterior a la acción, al diálogo, el encuentro y la colaboración con los hombres.

Simplificando diríamos que si a Ratzinger le preocupan sobre todo la verdad y la santidad de la inteligencia, a Bergoglio le preocupa sobre todo la santidad de la acción y de las manos. Si para Ratzinger están en el centro los universales de la razón, de la fe, de la humanidad, para Bergoglio en el centro están los universales del corazón, del sentimiento, de la misericordia, respecto de cada hombre concreto. Si a aquel le preocupaba la verdad ínsita de la fe y desde ella intentaba conferir luz y sentido a la vida humana para existir con razón y esperanza en medio de la duda y de la perplejidad, a éste le preocupa la vida diaria de los hombres en situación límite, la credibilidad de la iglesia que hoy se debe acreditar llegando a donde no llegan las instituciones de este mundo y 
haciendo aflorar los reversos de la realidad que los poderes ocultan. Estas son las preguntas que desvelan a Benedicto XVI: ¿Qué podemos y cómo debemos creer a la altura de nuestra conciencia histórica y del evangelio, recitando el Credo con sinceridad intelectual, en un mundo donde las filosofías, ideologías y políticas no saben qué hacer con la fe cristiana y cuando otras grandes religiones orientan en otra dirección? Estas son, en cambio, las situaciones históricas que desvelan a Bergoglio. ¿Cómo superar las estructuras políticas y económicas que han creado diferencias abismales entre los hombres, generando marginación y nuevas formas de pobreza, sin que disminuir las diferencias entre continentes, naciones, y grupos humanos sino incluso incrementándolas?

Ambas preocupaciones y propuestas son constitutivas del cristianismo. De la percepción de cada una y de la jerarquización entre ellas dependerá la actuación de cada papa, como la respuesta personal y proporcionada. El famoso Catecismo romano, elaborado en 1564-1566 por exigencia del Concilio de Trento y en el que se han inspirado los catecismos posteriores, articuló la ordenación interna de la vida cristiana en cuatro preguntas con las correspondientes respuestas, que anticipan en manera análoga las cuatro preguntas y respuestas de Kant ${ }^{7}$. Estas son las del Catecismo: ¿Qué tenemos que creer? ¿Qué debemos hacer? ¿Qué podemos recibir? ¿Qué y cómo debemos orar? A estas cuatro preguntas se responde así: a la primera con el Credo, a la segunda con los mandamientos, a la tercera con los sacramentos y a la cuarta con el Padre nuestro u oración del Señor.

A la luz de la acentuación de uno u otro de estos cuatro centros del cristianismo entendemos las polarizaciones que se han ido dando de él a lo largo de la historia en la iglesia oriental, en el catolicismo, en el protestantismo y en las éticas liberales. $\mathrm{Y}$ desde esos centros articuladores de sentido se entenderán también las distintas configuraciones que cada papa da a su ministerio según ponga en primer plano la vida interior de la iglesia o su acción en el mundo, la Biblia o la liturgia, la colaboración con las instituciones seculares o el testimonio de la vida escatológica tal como aparece especialmente en la existencia monástica.

\footnotetext{
7 «QQué puedo saber? Responde la metafísica. ¿Qué debo hacer? Responde la moral. ¿Qué me está permitido esperar? Responde la religión. ¿Qué es el hombre? Responde la antropología» (Kant, 1968: 4,448).
} 


\section{Otras cuestiones implicadas en nuestro tema}

\section{Extensión y límites de la autoridad pontificia}

a) La esencia y la historia. A la luz de la reflexión anterior surgen otras cuestiones de fondo: por ejemplo, la extensión y los límites tanto dogmáticos como jurídicos de la autoridad pontificia. ¿Qué puede hacer y qué no puede hacer ni omitir? ¿Hasta qué punto se rozan y codeterminan su autoridad doctrinal y su vida religiosa? ¿Condiciona su vida moral a su autoridad magisterial? Porque el papa es infalible solo en determinados momentos y bajo determinadas condiciones pero no es impecable. ¿Hasta dónde puede seleccionar sus tareas, dando primacía absoluta a unas sobre otras? ¿Hasta qué punto puede sustituir otras instancias de la Iglesia o relegarlas a la inactividad, tanto en personas como instituciones? Porque el papa no es la iglesia: es en la iglesia; su autoridad doctrinal no sustituye al pensamiento de los demás creyentes; él no es la revelación en persona sino un mero instrumento de su testificación, interpretación y la palabra final cuando los órganos normales de la iglesia no encuentren la solución a un problema o reclamen que universalice lo que de hecho ya es vivido en concordia general por todos. El papa no es señor del credo, de los sacramentos, de la vida litúrgica, de las iglesias particulares, ni del evangelio.

b) El 'ius divinum' y las configuraciones humanas. ¿Cuál es la 'substancia' del cristianismo? Estas son las realidades divinamente queridas, que pertenecen a la estructura constituyente de la iglesia, lo que los canonistas llaman el ius divinum. Yo las agruparía en los cuatro campos siguientes: 1) El Evangelio como contenido del Nuevo Testamento y sintetizado en el Credo. 2) Los sacramentos como signos eficaces divinamente queridos de la gracia divina y como quicio de la vida litúrgica de la iglesia. 3) El ministerio apostólico en su triple configuración: episcopado, presbiterado y diaconado. 4) La tradición apostólica concretada en los Concilios ecuménicos de manera normativa. En este sentido el papa es de derecho divino en cuanto obispo de Roma y en calidad de tal cumple en medio del colegio episcopal el lugar que San Pedro ocupaba en el colegio apostólico. Ahora bien, una es la realidad y otra la realización de ese ministerio, una cosa su esencia y otra la forma histórica de ejercicio, que la ha ido definiendo la iglesia, y en la que lo esencial es solo el hecho, la autoridad, la comunión con el resto de la iglesia y la responsabilidad para con ella. El ministerio del obispo de Roma no es eliminable como realidad teológica inherente a la Iglesia, 
pero su realización concreta permite varias figuras en su realización concreta.

\section{La identidad del catolicismo entre modernismo sincretista y monismo integrista}

a) La coordenada de unidad e inmutabilidad (Cristo) y la de novedad (Espiritu Santo). Otro tipo de preguntas fundamentales son las siguientes: ¿Hasta dónde pueden llegar esas variaciones o diferencias en el cristianismo? Su elasticidad, ¿hace posible que todo quepa en él? ¿Está ya todo tan fijado en él que nada nuevo puede aparecer o por el contrario está todo tan abierto que puede asumir cualquier influjo externo y todo elemento nuevo? ¿Qué relación hay entre la coordenada de unidad, fijeza e historicidad positiva inmutable, fundada sobre la persona y doctrina de Cristo por un lado, y por otro la coordenada de novedad, interiorización y actualización propias de la acción del Espíritu Santo? Este es el Paráclito enviado por Cristo a la Iglesia para que vaya recordando, personalizando y haciendo completa su verdad en la historia y en cada hombre. El catolicismo, ¿es un sincretismo y eclecticismo de tal cabida interior que se puede acomodar y puede responder de manera distinta a cada época? ¿Cómo se relacionan la unidad interna, es decir los elementos esenciales y permanentes, con la catolicidad interna, es decir, con su capacidad de relacionarse e integrar los valores que va creando la humanidad para ofrendarlos a Dios en alabanza y acción de gracias?

$\mathrm{Al}$ principio utilizamos una palabra y concepto sobre la que no hemos vuelto: «sincretismo». Ella puede tener dos significaciones diversas: una negativa, o la tendencia a mezclar realidades, ideas y prácticas diversas incoherentes entre sí; otra positiva, la capacidad de apropiarse e integrar dentro de una concepción propia y en unidad orgánica realidades de origen y sentido diversos. El cristianismo surgió en un contexto filosófico y religioso sincretista, tal como lo ofrecía el

8 El Concilio Vaticano II ha establecido los criterios para la integración, purificación y plenificación en la iglesia de las creaciones humanas exteriores a ella, con la finalidad no de apropiación posesiva sino para ofrecerlos a Dios creador en alabanza agradecida. «Como el reino de Cristo no es de este mundo (cf. Jn 18,36), la iglesia o el pueblo de Dios, introduciendo este reino, no disminuye el bien temporal de ningún pueblo, antes al contrario fomenta y asume, $y$ al asumirlas las purifica, fortalece y eleva todas esas capacidades, riquezas y costumbres de los pueblos en lo que tienen de bueno». Con. Vaticano II, Constitución dogmática sobre la Iglesia; Lumen Gentium, 13. Las asume para que la plenitud del mundo se integre en la alabanza divina: «La iglesia ora y trabaja para que la plenitud del mundo entero se integre en el pueblo de Dios, cuerpo del Señor y templo del Espíritu Santo, y en Cristo cabeza de todos, se rinda al creador universal y padre de todo honor y gloria»; Lumen gentium, 17, final. 
helenismo configurador del Mediterráneo, sobre todo en la cuenca oriental (Lilla, 1992; Klauck, 2012). Pequeño y débil externamente, cuajó frente a la sociedad configurando las instituciones mundanas a partir de la mitad del siglo IV. Esta afirmación y crecimiento se lleva a cabo desde dentro de sus dinamismos propios actualizados y acrecentados por discernimiento y prueba, por afirmación y distancia, por integración y trasformación primero frente a las dos grandes potencias espirituales del momento: judaísmo y helenismo. Luego yendo más allá de la religión, frente a la filosofía y la política, las instituciones del Estado, de la familia y de los grupos. Este proceso de asumir, descartar e integrar purificando, se continúa a lo largo de la historia de la Iglesia.

A. Harnack hizo en su día un análisis del progreso del cristianismo a partir del siglo IV para mostrar cómo fue posible que en menos de medio siglo se constituyera en elemento esencial configurador y ya no eliminable en la cultura y en sociedad; razón por la cual los emperadores tomaron la decisión de reconocerlo en vez de perseguirlo o excluirlo legalmente. Enumera los elementos esenciales de la nueva religión que le daban la capacidad de asumir todo lo anterior a la vez que de enriquecer lo propio, convirtiéndose así en algo aparentemente imposible: ser la religión universal y ser una religión excluyente. Esa unidad y complejidad al mismo tiempo le permitió afirmarse definitivamente frente a la religión política, la religión tradicional y los cultos mistéricos, porque incluía en un nivel más profundo lo que ellos ofrecían, a la vez que sus propios aspectos absolutamente nuevos (Harnack, 1924).

El cristianismo aparece como religión e iglesia inseparablemente unidos, y en cuanto tal ofrece cinco grandes aportaciones complejas y complementarias entre sí. 1) Es la religión judía simplificada, purificada y desligada de su carácter nacional, ahora universalizada. 2) Es la consumación y objetivación del aliento religioso propio del politeísmo y del sincretismo soteriológico oriental, pero incardinados ambos en el monoteísmo. 3) Es el heredero de la filosofía griega de la religión, purificada y determinada por las ideas madres de creación, redención, encarnación y resurrección. 4) Es un movimiento religioso que acoge y completa los impulsos morales del judaísmo tardío y del mundo grecoromano, prolongándolos con la idea de misericordia y del valor absoluto

\footnotetext{
9 El lector se queda levemente perplejo no ante la exposición de los datos sino ante la última valoración que hace Harnack de ese proceso sincretista. ¿Condujo finalmente a un enriquecimiento del evangelio con el encuentro e integración de culturas y religiones o a una helenización y romanización falsificadoras del sencillo y trasparente evangelio de Jesús centrado en la idea de la paternidad de Dios y del valor infinito del alma humana? En el intento, también originario, de despojo y purificación de esos elementos ajenos integrados, sitúa Harnack el inicio de la reforma luterana (pág. 331).
} 
de cada hombre derivado de la encarnación del Hijo, unido en cierta manera con cada hombre (Gaaudium et spes, 22) con especial atención a los pobres, desplazados, muertos. 5) Ofrece una vida de comunidad, que confiere a cada individuo, pobre o rico, esclavo o pretor, el sentido de dignidad ante Dios y de pertenencia a una fraternidad que se preocupa por él, y en la que encuentra la realización históricamente verificable de la revelación de Dios en forma humana.

Todo esto integrado en torno a un mensaje orgánico, propuesto en textos normativos comunes y referido a una figura histórica, no a una idea o un mito: la Persona viviente de Jesús de Nazaret con su destino sanador y dignificador, ejemplar en su muerte comprendida como victoria y perdón; y eficaz en resurrección en cuanto garantía de una vida eterna. Persona en la que se cree, a la que se ama, y con la que se configura el creyente desde dentro de la iglesia por dos caminos permanentemente abiertos: el litúrgico sacramental y el histórico moral.

Ese proceso de discernimiento y de selección, de integración y de rechazo, especialmente intenso en los orígenes, que se prolonga a lo largo de toda la historia de la iglesia se vuelve especialmente duro y difícil en los momentos de los grandes cambios culturales. Ellos obligan a retener lo vivo del origen diferenciándolo del 'eterno ayer', que es solo circunstancia arqueológica muerta. Esto explica también los choques entre distintas sensibilidades en la iglesia: la de quienes mirando hacia adentro de ella misma se inclinan a retener todo sin distinguir suficientemente la esencia y la circunstancia, y la de quienes quieren asumir todo lo que bulle en los movimientos nuevos de conciencia dentro o fuera de la propia iglesia, sin preguntarse por su coherencia con el meollo del cristianismo, su fecundidad en el orden de la santidad o de la misión y su posible potencia deletérea.

Frente a ciertas discusiones actuales sobre la diferencia entre los contenidos materiales del cristianismo (dogmáticos, morales, disciplinares, institucionales) y los correspondientes contenidos materiales de otras religiones e ideologías, con las que el cristianismo se relaciona y cuyos elementos asume, podemos aceptar como válido para el resto de las épocas el criterio del historiador antes citado referido a los primeros siglos de la iglesia.

La mirada crítica verá claramente que, en muchos casos, lo que es propio del cristianismo debe ser buscado menos en los detalles y en los aspectos particulares que en la configuración del conjunto y en el centro unificador a partir del cual está estructurado el universo cristiano. Por lo demás, la aceptación y asimilación de las influencias extranjeras pueden ser consideradas igualmente de manera positiva, como signos de la capacidad 
de integración del cristianismo, por la que puede fundir conjuntamente elementos diversos (Klauck, 2012: 21).

Esta es la gran cuestión a la hora de enjuiciar los giros del cristianismo y los vuelcos de la iglesia: ¿se mantienen y acrecientan esa configuración del conjunto y ese centro unificador o por el contrario se pierde la configuración total y desaparece el centro radial?

b) La doble tentación: fixismo-integrismo o modernismo-sincretismo. Estas son algunas de las cuestiones fundamentales substantes a un análisis inmediato de la actuación y comportamiento de cada uno de los papas. La tensión entre los distintos acentos del cristianismo es la garantía de una real catolicidad. La tentación permanente es doble: por un lado la de un modernismo-progresismo para el cual casi todo está abierto a la novedad creadora de la historia y conciencia humanas; y por otro la de un integrismo que juzga todo lo cristiano sobre todo o solo por un dogma y toda la acción de la iglesia en el mundo a la luz de la realización de uno de los mandamientos, de una propuesta teológica, de un modelo disciplinar y de una lectura particular de la Biblia.

La Iglesia es una y católica al mismo tiempo: unidad orgánica referida a la única persona de Cristo y catolicidad histórica referida al principio de su vida interior: el Espíritu Santo. Una y otra dimensión irán siendo realizadas en medio de las tempestades de la historia y de las fluctuaciones de cada persona. Ambas realidades convierten a la iglesia en un misterio de fe, por ser fruto de la acción de Dios en el corazón de la historia, y al mismo tiempo en un enigma por ser resultado también de la libertad de los hombres, capaces de la verdad, bondad y belleza sumas pero no menos capaces del pecado, de la maldad y de la violencia igualmente sumas. Iglesia entrañable por ser eco fiel y permanente tanto del amor como del perdón de Cristo; iglesia extraña por ser resultado de ese genio de grandeza y de ese monstruo de maldad que puede ser en cada momento el hombre.

\section{Vuelcos y giros o redescubrimientos y reformas en la Iglesia. Diez tesis}

El natural entusiasmo y legítima esperanza con que muchas personas y grupos han acogido los gestos y palabras de Francisco tales como evangelio, pobreza, misericordia, servicio a los marginados y excluidos, reforma y abertura misionera, ha llevado a algunos a considerar que por fin ahora comenzaba la iglesia católica a ser verdaderamente cristiana y a 
vivir según el evangelio. Han considerado que tales actitudes significaban en la iglesia algo similar a lo que el giro de Copérnico significó en la astronomía de su siglo o la física de Einstein en el siglo XX. ¿Está dándose realmente con Francisco un cambio de eje vertebrador en el pensamiento de la iglesia y en unos nuevos criterios a la hora de orientar su acción? ¿Estamos ante una nueva iglesia o ante una iglesia renovada? Cuándo decimos que otra iglesia es posible, ¿qué decimos? ¿Hay contradicción entre Benedicto XVI y Francisco?

\section{Cada hombre en su historia}

Cada generación encarna unos ideales y proyectos con unos sueños acariciados y con unos miedos asumidos o reprimidos, casi siempre en relación de amor y odio con las generaciones anteriores. Al hablar de papas diferentes hay que comenzar hablando de las diferencias temporales y coyunturales en medio de las que han ejercido su ministerio. No son en 2005 y en 2014 los mismos tiempos, las mismas atmósferas, los mismos polos colectivos de interés, las mismas vigencias y evidencias públicas. Su ministerio ha sido ejercido mediante una acción determinada por sus propias ideas y proyectos anteriores pero no menos en reacción-respuesta a las situaciones que encontraron al llegar al cargo con las esperanzas proyectadas sobre ellos. No ha sido el mismo tiempo interior el de Benedicto XVI y el de Francisco; por consiguiente, en principio, no son comparables.

\section{Identidad y cambio en los seres vivos}

No se puede hablar de 'giro copernicano' ni de 'vuelcos einstenianos' en la Iglesia, ya que nada esencial ha sido negado, o sido sustituido por otras realidades objetivas de su vida o por otras formulaciones que interpreten en manera totalmente distinta la revelación divina. Nada ha cambiado en el orden del creer (Credo), del recibir (Sacramentos), del hacer (Mandamientos), del orar (Padre nuestro). Han cambiado los acentos, las primacías, las relaciones con el exterior, ciertas regulaciones disciplinares pero nada de lo que debemos considerar como constituyente o, expresado con lenguaje jurídico, de derecho divino. Todo ser vivo crece cambiando, integrando y desechando. Newman con su obra Ensayo sobre el desarrollo de la Doctrina cristiana (de 1845) expuso la lógica de este desarrollo homogéneo y estableció los criterios para diferenciar un real crecimiento de una perversión del origen. 


\section{Ecclesia semper reformanda o la necesidad permanente de reforma}

¿Se puede hablar de 'revolución en la Iglesia'? No, si se entiende por tal la inversión de las realidades constituyentes y normativas: el evangelio, los signos sacramentales, el ministerio ordenado, la vocación a la santidad y a la misión, la esperanza escatológica, la conformación teologal de la vida cristiana, la tradición apostólica tal como ha sido formulada en los Concilios ecuménicos o sellada por la concordia del episcopado con el obispo de Roma a la cabeza en un sentido y por el 'sentido de la fe' en otro. Se puede hablar de 'revolución' en el sentido de reforma profunda, de nuevos métodos, de superación de olvidos, de descubrimiento de perspectivas bíblicas antes no percibidas con tal intensidad de aceptación de nuevos imperativos históricos. Realidades todas ellas que pueden ser muy significativas e incidir profundamente en las conciencias. En el evangelio de San Juan el envío del Espíritu Paráclito por Cristo es justamente para irnos llevando a la verdad que se va haciendo completa al filo del tiempo para ser así verdad connatural de cada generación en una doble vertiente: de su afirmación y profundización por un lado, de la crítica y corrección del pensamiento general por otro.

\section{La primavera: su novedad y su continuidad con otoño e invierno}

Se podría también hablar de una 'primavera en la iglesia', en el sentido de un florecimiento y maduración de semillas sembradas en una fase anterior y a las que no se había cultivado o incluso a las que se había reprimido o intentado arrancar del suelo de las conciencias. La metáfora, sin embargo, nos obliga a recordar que la primavera es la estación que está al final de un proceso que incluye otras dos: el otoño de la sementera y el invierno de la maduración hacia abajo y hacia adentro. Es decir tiempo de aparición de unas flores y frutos que el trabajo anterior de otros ha hecho posibles.

\section{La acción del único Espíritu Santo mediante hombres distintos}

Si ahora ya concretamente nos referimos a estos dos papas podemos decir que, queriendo hacer ambos lo mismo, de su acción resulta algo distinto. Ellos no han pretendido otra cosa que ejercer el ministerio petrino como servicio a la fe, a la comunión eclesial, al sostén moral de las conciencias y en amorosa atención a los problemas del mundo, pero haciéndolo cada uno desde su historia anterior, biografía, 
psicología personal y peculiar percepción de los problemas, ha resultado algo distinto. El Espíritu Santo no maneja robots ni mecanos sino hombres libres. A través de la diferencia en la convergencia se explicitan la riqueza y la tensión entre la unidad interna (que no es la uniformidad) y la catolicidad interna (que no es la mera diversidad amorfa).

\section{Los polos de sentido en el pensamiento de cada uno de los papas}

Benedicto XVI puso en el centro de su atención la verdad, generado de amor y de libertad, como primacía de la vida humana y la fe en el Dios revelado en Cristo como primacía tanto de la existencia personal del cristiano como del diálogo con la razón y la cultura. Francisco I, en cambio, ha puesto en primer plano la justicia como primacía de la vida social y política, mientras que ha puesto como primacía de la vida cristiana la misericordia, la pobreza, la atención a los pobres, la presencia en los 'no-lugares de humanidad', donde prevalecen la violencia, el crimen, el desamor. ¿Qué urge más a corto plazo? ¿Qué es, en cambio, más fecundo a largo plazo?

\section{La correspondencia de estos acentos en el Nuevo Testamento}

Ambos papas actualizan dimensiones constituyentes del Nuevo Testamento. A éste pertenecen cada uno de sus veintisiete libros, que se codeterminan entre sí, ya que cada uno cuenta con los otros y no es separable de los demás. No los leemos todos a la vez, pero ninguno excluye la integración de la lectura del resto. Así San Juan y las Cartas de la cautividad definen el evangelio de nuestra salvación como «logos tes aletheias = palabra (razón, sentido, idea) de verdad» (Ef 1,13; Col 1,5). Estos dos términos son claves en el pensamiento de Benedicto XVI. Por su parte San Pablo define ese mismo evangelio como «dynamis tes soterías $=$ potencia de salvación para todo el que cree sea judío o gentil porque en él se revela la justicia de Dios» (Rm 1,16-17), más en la línea de la acción, sanación, redención y justificación. Unas y otras son necesidades originarias de la vida humana. A unas y a otras se refiere el mensaje cristiano; a unas y a otras sirven la iglesia y todos los papas.

\section{Correlación entre esperanzas proyectadas por la sociedad actual y respuestas ofrecidas por Francisco}

Francisco ha suscitado inmensas esperanzas en una comunicación directa con las conciencias y necesidades actuales. La gran pregunta es si 
estas esperanzas son expresión más de nuestras necesidades que de sus capacidades. Una humanidad herida, vulnerable, débil y amenazada está anhelante de ayuda, apoyo, confirmación de su situación. La sociedad europea particularmente se halla en una situación de perplejidad y de debilidad profunda, sin capacidad de sufrimiento, medicalizada en un alto porcentaje, sorda para los grandes proyectos e incapaz de heroísmo. Está como recluida en un individualismo autocomplaciente. Han proliferado las técnicas psicoterapéuticas, los gimnasios, las clínicas de relajación y de interiorización. Para cualquier sufrimiento, decepción, desastre, impotencia, se reclama la ayuda de un psicólogo. En ese contexto la gran cuestión es si las esperanzas que ha suscitado Fran cisco son resultado de sus gestos y palabras o son más bien de nuestras necesidades. El gran temor es si a este entusiasmo no sucederá una gran desilusión ya que esas dolencias de los humanos requieren ayuda exterior pero no menos fuerza interior, esfuerzo propio, ayudas de naturaleza, intelectiva, volitiva y activa; aguas de vida que hay que sacar cada uno con el propio balde del propio pozo; respuestas personales y sociales, no solo religiosas.

\section{Las respuestas ocasionales y personales y las objetivas y universales}

El Papa es el obispo de Roma y en cuanto tal a la cabeza de la Iglesia católica y en consecuencia exponente e intérprete público de lo que ella cree como prolongadora y actualizadora autorizada del mensaje de Cristo, refiriéndolo a cada situación de vida y proponiéndolo como norma para la acción. Lo que él hace y dice no es solo su opinión personal o su particular actuación pastoral: él es y aparece como la autoridad ejemplar y normativa para toda la iglesia católica. En este sentido alguna palabra suya, en si perfectamente válida, ha suscitado perplejidad y preguntas; por ejemplo, cuando se le pregunto qué pensaba de un homosexual y respondió: «¿Quién soy yo para juzgar a nadie?». Es lo que referido a una persona todos debemos responder, ya que cada uno es un absoluto ante Dios. Pero en la medida en que la pregunta se haga no en referencia a personal particular sino de forma objetiva: ¿Cómo enjuicia la iglesia la realización homosexual decidida, permanente y completa? Así planteado el problema reclama una respuesta objetiva; a no ser que alguien diga que es una cuestión moralmente indiferente (adiafora) sobre la que la fe y la iglesia no tienen nada que decir. Y si lo tienen, ¿quién es quién para responderla sino el Papa? Sin duda lo hará en otro momento no en un marco ocasional y personal sino objetivo y 
universal, personalmente o por los órganos institucionales con los que se ayuda.

\section{Los signos complejos: negación del pasado o abertura a un futuro distinto}

El Papa puede manifestar su voluntad y autoridad por palabras, por signos y por hechos, tanto en el orden de la fe apostólica recibida, como de la disciplina canónica y de las normas pastorales. En este sentido cuando él hiciere algo que aparentemente es contrario a las normas vigentes, eso significa que las está derogando, a no ser que explique que se trata de una excepción fundada, o de su voluntad públicamente manifestada de inaugurar un nuevo método de acción disciplinar o pastoral. El caso al que vuelven las preguntas es el del bautismo de un niño de padres no casados sacramentalmente. El hecho en sí no es extraño: desde siempre en la iglesia los padrinos proveyeron ante la iglesia a la formación cristiana de cada bautizado. La praxis pastoral de la iglesia en los últimos siglos y sobre todo en los últimos decenios exigía la preparación de los padres para el bautismo de sus hijos y la garantía de que iban a educarlos en la fe católica viviéndola en casa, familia y educación. ¿Cómo hacer esa trasmisión de la fe sin poseerla? Sin duda el Papa tenía razones graves para realizar un acto que aparentemente iba en contra de esta praxis pastoral. ¿No hubiera sido bueno que se nos hubiera orientado con alguna información o declaración previa para que lo hubiéramos podido entender en su verdadero sentido, liberados de la pregunta inevitable? ¿Si había graves razones, podrían saberse? $\mathrm{O}$, ¿es el primer paso para una praxis pastoral nueva y cual en concreto?

Por estas y otras razones hay que otorgar confianza y dar más tiempo al Papa para que él actúe con mayor explicitud y para que nosotros podamos tener una visión completa de sus intenciones y valorarlas con mayor justicia. Esta será posible cuando sus gestos se traduzcan en palabras normativas y se verifiquen en decisiones vinculantes.

\section{REFERENCIAS}

-González de Cardedal, O. (2013). Dios en la ciudad. Ciudadanía y cristianía. Salamanca: Sígueme.

-González de Cardedal, O. (2014): Europa en la alternativa. Vida Nueva (4 al 7 de enero), 23-35. 
-Harnack, A. von (1924). Die Mission und Ausbreitung des Christentums in den ersten drei Jahrbunderten. Berlin.

-Kant, I. (1968). Logik. Einleitung. En Kant Werke 5. Darmstadt: Wissenschaftliche Buchgesellschaft.

-Klauck, H. J. (2012). L'environnement religieux gréco-romain du christianisme primitif. Paris: Cerf.

-Lilla, S. (1992). Sincretismo. En A. di Berardino (Dir.), Diccionario patrístico y de la antigüedad cristiana (II, págs. 2012-2014). Salamanca: Sígueme.

-López Cambronero, M. \& Merino Escalera, F. (2013). Francisco el Papa Manso. Barcelona: Planeta Testimonio.

-Nietzsche, F. (1983). Más allá del bien y del mal. (A. Sánchez Pascual, Trad.). Madrid: Alianza.

-Ratzinger, J. (1997). Mi vida. Recuerdos (1927-1977). Madrid: Ediciones Encuentro.

-Ratzinger, J. (2007). Jesús de Nazaret. I: Desde el bautismo a la Transfiguración. Madrid: Planeta.

-Ratzinger, J. (2011). II. Desde la Entrada en Jerusalén hasta la Resurrección. Madrid: Planeta.

-Ratzinger, J. (2012). III: Prólogo: Los relatos de la infancia. Madrid: Planeta.

Sumario: Introducción: El último medio siglo y el último decenio de la iglesia; I. Dos hechos decisivos inmutadores de una historia secular; 1. La renuncia de Benedicto XVI; 2. La elección de Francisco; II. Una misma misión para dos personas y dos destinos; 1. La realidad del ministerio petrino; 2. Tres configuraciones históricas diversas; III. Dos proyectos diferenciados para la misma iglesia; 1. La propuesta de Pablo VI: «Iglesia hacia adentro-Iglesia hacia fuera»; 2. Programa de Benedicto XVI a la luz de su primera encíclica Deus caritas est. La preocupación doctrinal en el centro. La fe; 3. Continuidad o discontinuidad de Francisco con su predecesor; 4. Programa de Francisco a la luz de su primer documento: La alegría del evangelio. La preocupación social en el centro. La caridad-misericordia; IV. Otras cuestiones teológicas implicadas en nuestro tema; 1. Extensión y límites de la autoridad pontificia; 2. La elasticidad del catolicismo entre dos extremos; V. Vuelcos y giros o redescubrimientos y reformas en la iglesia. Diez tesis; 1. Cada hombre en su historia; 2. Identidad y cambio en los seres vivos; 3. Ecclesia semper reformanda o la necesidad permanente de reforma; 4. La primavera: su novedad y su continuidad con otoño e invierno; 5. La acción del único Espíritu Santo mediante hombres distintos; 6. Los polos de sentido en el pensamiento de cada uno de los papas; 7. La correspondencia de estos acentos en el Nuevo Testamento; 8. Correlación entre las esperanzas proyectadas por la sociedad sobre Francisco y sus respuestas; 9. Las respuestas ocasionales y personales y las objetivas y universales; 10. Los signos complejos: negación del pasado o abertura a un futuro distinto; Referencias. 